\title{
FEATURE
}

\section{An International Comparison of Virtual Reference Services}

\section{Lawrence Olszewski and Paula Rumbaugh}

Lawrence Olszewski is Director, OCLC Library, Dublin, Ohio. Paula Rumbaugh is Senior Product Analyst, OCLC, Dublin, Ohio. Submitted for review July 2, 2009; accepted for publication September 6, 2009.
Reference \& User Services Quarterly, vol. 49 , no. 4 , pp. 360-368

(c) 2010 American Library Association. All rights reserved.

Permission granted to reproduce for nonprofit, educational use.
In an attempt to determine and compare the nature of virtual reference services in both academic and public libraries outside the United States, we analyzed data compiled from webform transactions e-mailed to and from libraries via the QuestionPoint virtual reference service. The study reviewed transactions that were handled during a typical week in April 2006 and in April 2008 by twenty-three libraries in ten countries: Australia, Belgium, France, Germany, Mexico, the Netherlands, Slovenia, South Africa, Sweden, and the United Kingdom. We analyzed transactions by language, type of institution (public or academic), question type (access, bibliographic, or subject), answer type, subject, and response time, with attention to how these characteristics had changed in two years. The results of the study provide insight into how students and the general public use virtual reference services in various countries and how service efficiency differs among countries and library types.

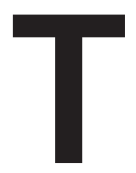

he use of virtual reference is becoming more prevalent in libraries throughout the world, yet studies of the use of transactions from virtual reference interchanges in non-U.S. countries have not appeared widely in the literature.

In this paper, we use "virtual reference" to mean asynchronous communi- cations between patron and library; we do not address synchronous (or chat) reference. This study is one of the first to examine this aspect of library communication from a multinational point of view for both academic and public libraries. This study is-as far as is known-the first that considers virtual reference use in Belgium, Mexico, or Slovenia.

\section{PURPOSE}

The purpose of this study was to discover similarities and differences in virtual reference services in non-U.S. countries. To make these comparisons, we examined such factors as country, language, type of question and answer, subject, response time, and user status.

We also wanted to know if there were any changes of those factors between 2006 and 2008, and if service efficiency (measured by turnaround times) had improved.

\section{LITERATURE REVIEW}

We confined our literature search to empirical and case studies conducted in the ten countries under examination here in publications indexed in Library 
Literature and LISA: Library and Information Science Abstracts since 2000.

\section{Australia}

Porter's discussion of thirty transcripts from a chat reference service aimed at off-campus nursing students at La Trobe University found that 30 percent of the questions asked revolved around document delivery. ${ }^{1}$ Lee's study of forty-seven e-mail and chat reference transactions at Murdoch University measured, among other criteria, turnaround time in answering e-mail (mean delay of six hours) and question and answer types (e-mail questions tended to have a higher proportion of administrative questions than chat and required fewer techniques of the reference interview). ${ }^{2}$ Sullivan analyzed ninety-six question-and-answer pairs from the Bayside Library Ask-aLibrarian service in Victoria and found that 47 percent of the reference questions were classified as research queries. ${ }^{3}$ Davis and Scholfield's report on a collaborative arrangement between an Australian and a Scottish library for 24/7 coverage found that such an agreement cut down on the turnaround time of answering e-mail inquiries but found procedural and administrative inquiries hard to deal with. ${ }^{4}$ Davis' report on an instant-messaging (IM) trial with the National Library of Australia found that 61 percent of inquiries were general reference, 73 percent were completed during the IM sessions, 40 percent ended in ten minutes or less, and 91 percent of users rated the services as "very good" or "excellent." "5

\section{France}

DiPietro and Calenge, as well as Bazin, discuss the Guichet du Savoir, an online information service offered by the Lyon Municipal Library, but make no comparisons to other libraries. ${ }^{6}$ Nguyen talks about virtual reference from a theoretical perspective and thus eschews any mention of specific virtual library services. $^{\top}$

\section{Germany}

Simon found that users have trouble locating e-mail reference services on library websites. ${ }^{8}$ In a separate study, Simon analyzed how Chinese and German students use e-mail information. ${ }^{9}$

\section{The Netherlands}

Doek talks about the chat service of Bibliothek van de Universiteit van Amsterdam (UVA) (one of the libraries analyzed here). ${ }^{10}$

\section{South Africa}

Darries found that among the twentysix academic libraries surveyed, the majority of libraries provided electronic reference service via e-mail and the library website, but these services had low levels of use. ${ }^{11}$

\section{Sweden}

Jonsby studied the Ask the Library service in nineteen public libraries and found that the service's time limit of three days was appropriate, as most inquiries were answered in the same day; school students were the largest user group; literature topped the field of inquiries (37 percent); and the time it took to answer an inquiry was often longer than it would have been if the user had been present in the library. ${ }^{12}$

\section{The United Kingdom}

Davies' study of four small rural libraries that experimented with replacing all reference books with virtual access found that searching for answers to simple questions online was too inconvenient for users. ${ }^{13}$ Beard, Bottomly, and Geeson's survey of thirty users of a virtual e-mail reference service at Bournemouth University found that two-thirds of the questions asked were subject-related. ${ }^{14}$ Cloughley analyzed the results of ten reference questions sent to three U.S. and two UK free digital reference services and found that the average response time varied from fifteen minutes to sixty-seven hours, correct answers were given at only two of the services, and most did not provide sources. ${ }^{15}$ Chowdhury and Margariti found that among five libraries in
Scotland, the actual turnaround time for answering e-mail questions was faster than was stated on their webpages and that a great majority of inquiries were "mechanical" questions on how to use IT resources rather than specific subject requests. ${ }^{16}$

\section{METHOD}

\section{Data Collection}

We compiled files of questions that were e-mailed to twenty-three QuestionPoint libraries in Australia, Belgium, France, Germany, Mexico, the Netherlands, Slovenia, South Africa, Sweden, and the United Kingdom via webform-and the resulting librarianpatron exchanges-for the week of April 3, 2006. The week was chosen because it was within the school year of the countries in the study and had no known conflicts with national or religious holidays in any of the countries. For each library, we randomly selected twenty-five questions that were asked during that week; if a library had fewer than twenty-five questions for that week, we gathered transactions from subsequent weeks until the twenty-fivequestion quota was met or until the end of the month. To ensure the broadest geographic coverage possible, we included public, academic, and national libraries. A specialized business school in Germany was excluded, however, because we felt its specialization would skew the results.

Another sample of transactions from the same libraries was gathered for the week of April 7, 2008. However, three libraries-one each in Belgium, Sweden, and the United Kingdom-had since dropped the service, so we had no transactions from them and worked instead with only the transactions from the remaining twenty libraries. We compiled 991 questions-515 from the first study and 476 from the second. To guarantee privacy, all user identification information-name, address, telephone, as well as names mentioned in the transcripts-was stripped from all the transactions in both samples. 


\section{FEATURE}

\section{Coding}

We coded each transaction according to how it fit into the following categories:

- Type of institution: academic or public. Of the twenty-three institutions in the study, eighteen were academic, four were public, and one was national. The data for the one national library were rolled into those for public libraries because we felt that the users and questions asked there more closely resembled those in public libraries.

- Language. Each transaction was coded according to the language of the question, not the answer (which was occasionally in a different language). Questions were asked in a total of eleven languages: Afrikaans, Arabic, Dutch, English, French, German, Hungarian, Polish, Slovenian, Spanish, and Swedish, though three (Arabic, Hungarian, and Polish) were used only once.

- Question type: access, bibliographic, or subject. Access questions were those relating to library policy (book returns, fines, loan extensions, etc.) or how to access library resources (databases, catalogs, software, etc.). Bibliographic questions were those in which the user asked if the library owned a specific title or could obtain it. Subject questions called for specific information on a subject. Test questions, incomplete questions, or otherwise inappropriate questions (such as spam or someone obviously not serious) were excluded from the final sets.

- Answer type. Seven answer-type codes were applied to the questions (see table 1).

- User status. Questions from academic institutions were coded according to whether the users were undergraduate students, graduate students, or staff (which may include faculty) if that information was requested and supplied on the webform. We coded 417 questions this way; many of the non-Anglophone libraries did not track this demographic.

- Subject classification. We coded 663

\section{Table 1. Answer Type Codes}

\begin{tabular}{|c|c|c|}
\hline Answer Type & Code & Explanation \\
\hline Confirm & $\mathrm{C}$ & E.g., confirm ILL request or book return \\
\hline Clarification & $\mathrm{CL}$ & Librarian requests clarification \\
\hline Fact & F & $\begin{array}{l}\text { Factual answer, either within the response or as an at- } \\
\text { tachment }\end{array}$ \\
\hline Instructions & I & How to do something or how to follow policy \\
\hline $\begin{array}{l}\text { Pathfinder/ } \\
\text { bibliography }\end{array}$ & $\mathrm{P}$ & $\begin{array}{l}\text { Includes specific titles or URLs to refer to with links } \\
\text { when appropriate }\end{array}$ \\
\hline Refer elsewhere & $\mathrm{R}$ & Direct to another library or person or place \\
\hline No answer & NA & No additional guidance or no answer given \\
\hline
\end{tabular}

questions by subject using the one hundred broad-level subjects of the Dewey Decimal Classification (DDC) system (000-990). A subject class was assigned to subject and bibliographic questions, and occasionally to access questions when a subject was inherent to the nature of the help request.

- Response time. The time (in hours) between when the question was first asked and the library's first response to the patron was recorded. For the sake of uniformity, weekends were factored in as part of the time.

\section{RESULTS AND DISCUSSION}

\section{Language}

English was used by the greatest number of users, mostly because of the six institutions located in the two Anglophone countries (the United Kingdom and Australia). Among the non-Anglophone countries, however, Dutch comes out on top with the greatest percentage of questions asked (23 percent), though German and French were close behind (22 and 20 percent, respectively). Some observations:

- English was used at all but four libraries, including three French, two Dutch, and three German libraries.

- Eleven institutions handled at least two languages, including those in South Africa, where both Afrikaans and English (among other languages) are official. Three libraries handled three different languages, and a German public library handled six.

- No primarily English-language institutions handled any language other than English. In libraries where questions were asked in languages other than that of the library's location, English was the second language of choice, used twice in Belgium (where none were in Dutch, the country's other official language), twelve times each in France and Germany, and twentyeight times in the Netherlands.

- One question each was received in Hungarian, Polish, and Swedish in a German public library-and answered in kind. The one Arabic question sent to a French public library was answered in French.

- Lest it seem that only Anglophone countries are monolingual, in three non-Anglophone countries-Mexico, Slovenia, and Sweden-users asked all questions in their country's official language.

\section{Question Types}

The breakdown of question types is nearly the same for access and subject questions (see table 2). However, the variances among countries are notable. More than three-fourths of the questions asked in Belgium (which had only academic libraries in the study) were 
access questions. At the other end of the scale, Mexico (also academic-only) had only 6 percent access questions. France (all public libraries) also had relatively few access questions, and Sweden (public only) had none.

On the other hand, Mexico and Sweden had the highest percentages of subject questions, and the top two countries for access questions (Belgium and Australia) were the bottom two for subject questions. The percentages were remarkably consistent for the two years studied.

When we break down questions by type of institution, almost half the academic questions in all disciplines were access questions, and subject and bibliographic questions were nearly tied for second place. However, in public libraries, three-fourths of the questions were subject questions; bibliographic and

Table 2. Percentage of Question Types by Country

\begin{tabular}{lccc}
\hline Country & Access (\%) & Bib (\%) & Subject (\%) \\
Australia & 70 & 17 & 13 \\
Belgium & 76 & 12 & 12 \\
France & 11 & 27 & 62 \\
Germany & 27 & 29 & 44 \\
Mexico & 6 & 6 & 88 \\
Netherlands & 37 & 22 & 41 \\
Slovenia & 25 & 22 & 53 \\
South Africa & 42 & 24 & 34 \\
Sweden & 0 & 13 & 87 \\
United Kingdom & 50 & 32 & 18 \\
\hline Total & $\mathbf{3 9}$ & $\mathbf{2 4}$ & $\mathbf{3 7}$ \\
\hline
\end{tabular}

Note: Percentages for Belgium and Sweden reflect 2006 data only. UK data represent one fewer institution in 2008.

Table 3. Results of Questions and Answers by Library Type

\begin{tabular}{|c|c|c|c|c|c|c|c|c|c|}
\hline \multirow{2}{*}{$\begin{array}{l}\text { Library } \\
\text { Type }\end{array}$} & \multirow{2}{*}{$\begin{array}{l}\text { Question } \\
\text { Type }\end{array}$} & \multicolumn{7}{|c|}{ Answer Type } & \multirow[b]{2}{*}{ Total } \\
\hline & & C & $\mathrm{CL}$ & $\mathbf{F}$ & I & $\mathbf{P}$ & $\mathbf{R}$ & NA & \\
\hline \multirow[t]{3}{*}{ Academic } & A & 100 & 3 & 7 & 228 & 0 & 22 & 11 & 371 \\
\hline & BIB & 56 & 4 & 11 & 82 & 11 & 31 & 12 & 207 \\
\hline & S & 9 & 2 & 15 & 90 & 63 & 31 & 12 & 222 \\
\hline \multicolumn{2}{|c|}{ Academic Total } & 165 & 9 & 33 & 400 & 74 & 84 & 35 & 800 \\
\hline \multirow[t]{3}{*}{ Public } & A & 6 & 0 & 0 & 7 & 0 & 1 & 0 & 14 \\
\hline & $\mathrm{BIB}$ & 10 & 0 & 11 & 4 & 3 & 4 & 1 & 33 \\
\hline & S & 1 & 3 & 43 & 7 & 72 & 9 & 9 & 144 \\
\hline \multicolumn{2}{|c|}{ Public Total } & 17 & 3 & 54 & 18 & 75 & 14 & 10 & 191 \\
\hline \multicolumn{2}{|c|}{ Grand Total } & 182 & 12 & 87 & 418 & 149 & 98 & 45 & 991 \\
\hline
\end{tabular}

access questions made up the final quarter. These percentages, too, were fairly consistent from 2006 to 2008, though public library bibliographic questions decreased from 19 to 13 percent.

The high percentage of subject questions in Sweden (87 percent), France (62 percent), Germany (44 percent), and the Netherlands (41 percent) may reflect the large number of public libraries in this study from those countries, though we must note again that 88 percent of the Mexican academic questions were also subject questions. Even in Slovenia, with only one library (an academic), slightly more than half were subject questions.

\section{Answer Types}

The tendency toward subject questions in public libraries is further supported when we look at answer types (see table 3). Although answer type naturally depends somewhat on the question type, it remains significant that half of all academic library questions were answered with instructions compared to less than a tenth of the public library questions.

Even looking at subject questions alone, 41 percent of academic questions were answered with instructions compared to only 5 percent of subject questions in public libraries. Furthermore, public libraries gave factual answers to subject questions almost one-third of the time, and academic libraries did so less than one-tenth of the time.

This higher percentage of instructional answers in academic institutions, and the correspondingly higher percentage of factual answers in public institutions, is not surprising if (as in the United States) public libraries and academic libraries differ in mission: public libraries tend to focus on freedom of information for all, and they tend to do the research for patrons. Academic libraries, on the other hand, focus on how to find information, so they tend to offer resources and instruction on how to use them.

\section{User Status}

Of the 417 transcripts on which users indicated a status, 51 percent of the 


\section{FEATURE}

participants were undergraduates, 38 percent were graduates, and the remaining 11 percent were staff. Graduate students asked access questions at a slightly higher rate than did undergraduates, and undergraduates asked subject questions at a higher rate than did graduate students. Graduate-student question types were 62 percent access, 25 percent bibliographic, and 13 percent subject; undergraduatestudent questions were 56 percent access, 18 percent bibliographic, and 26 percent subject.

This dimension was one of the few in our study that changed significantly between 2006 and 2008, but the changes were parallel in both student groups; access questions increased (by 14 percent among graduates and by 4 percent among undergraduates), and bibliographic and subject questions decreased in both groups.

\section{Subject Classification}

The evaluated transactions show that public libraries spend most of their email virtual reference time on subject questions, which make up 75 percent of all questions they received. But as noted earlier, 88 percent of the Mexican academic questions were subject-related. Slovenian and South African academic libraries also had significant portions of subject questions.
Although only 18 percent of its questions were subject-related, the United Kingdom nevertheless had the second largest number of subject questions (ninety-four), so it is noteworthy that it had a fairly even distribution throughout the subject categories. However, South Africa, with the largest subject set, had a much less even distribution that was concentrated heavily in law, business, and medicine (see table 4).

Sixty-two percent of all questions for both years fit the criteria for assigning a DDC number (the percentage was virtually identical for both years).

As figure 1 shows, nearly half of all subject-related questions were about humanities subjects, while the remainder are equally split between the social sciences and sciences.

The breakdown by broad discipline varied considerably, however, depending on library type. In academic libraries, slightly more than one-third of all questions asked were about humanities subjects, but the sciences and social

Figure 1. Breakdown of Subjects by DDC

Table 4. Subject Classification of Questions by Country

\begin{tabular}{|c|c|c|c|c|c|c|c|c|c|c|c|}
\hline DDC & Australia & Belgium & France & Germany & Mexico & Netherlands & Slovenia & $\begin{array}{l}\text { South } \\
\text { Africa }\end{array}$ & Sweden & $\begin{array}{l}\text { United } \\
\text { Kingdom }\end{array}$ & Total \\
\hline 000 & 0 & 0 & 13 & 14 & 1 & 5 & 3 & 4 & 0 & 6 & 46 \\
\hline 100 & 3 & 1 & 3 & 0 & 2 & 1 & 0 & 1 & 1 & 1 & 13 \\
\hline 200 & 0 & 1 & 3 & 4 & 0 & 2 & 0 & 2 & 0 & 7 & 19 \\
\hline 300 & 16 & 2 & 13 & 22 & 12 & 21 & 9 & 57 & 0 & 24 & 176 \\
\hline 400 & 1 & 0 & 3 & 2 & 3 & 4 & 0 & 3 & 2 & 5 & 23 \\
\hline 500 & 2 & 1 & 4 & 6 & 5 & 11 & 1 & 12 & 1 & 4 & 47 \\
\hline 600 & 11 & 0 & 4 & 5 & 7 & 26 & 8 & 47 & 5 & 18 & 131 \\
\hline 700 & 1 & 1 & 20 & 8 & 1 & 8 & 3 & 4 & 3 & 6 & 55 \\
\hline 800 & 3 & 0 & 12 & 11 & 1 & 5 & 6 & 11 & 2 & 9 & 60 \\
\hline 900 & 1 & 0 & 9 & 20 & 0 & 8 & 4 & 5 & 2 & 14 & 63 \\
\hline $\begin{array}{l}\text { Grand } \\
\text { Total }\end{array}$ & 38 & 6 & 84 & 92 & 32 & 91 & 34 & 146 & 16 & 94 & 633 \\
\hline
\end{tabular}



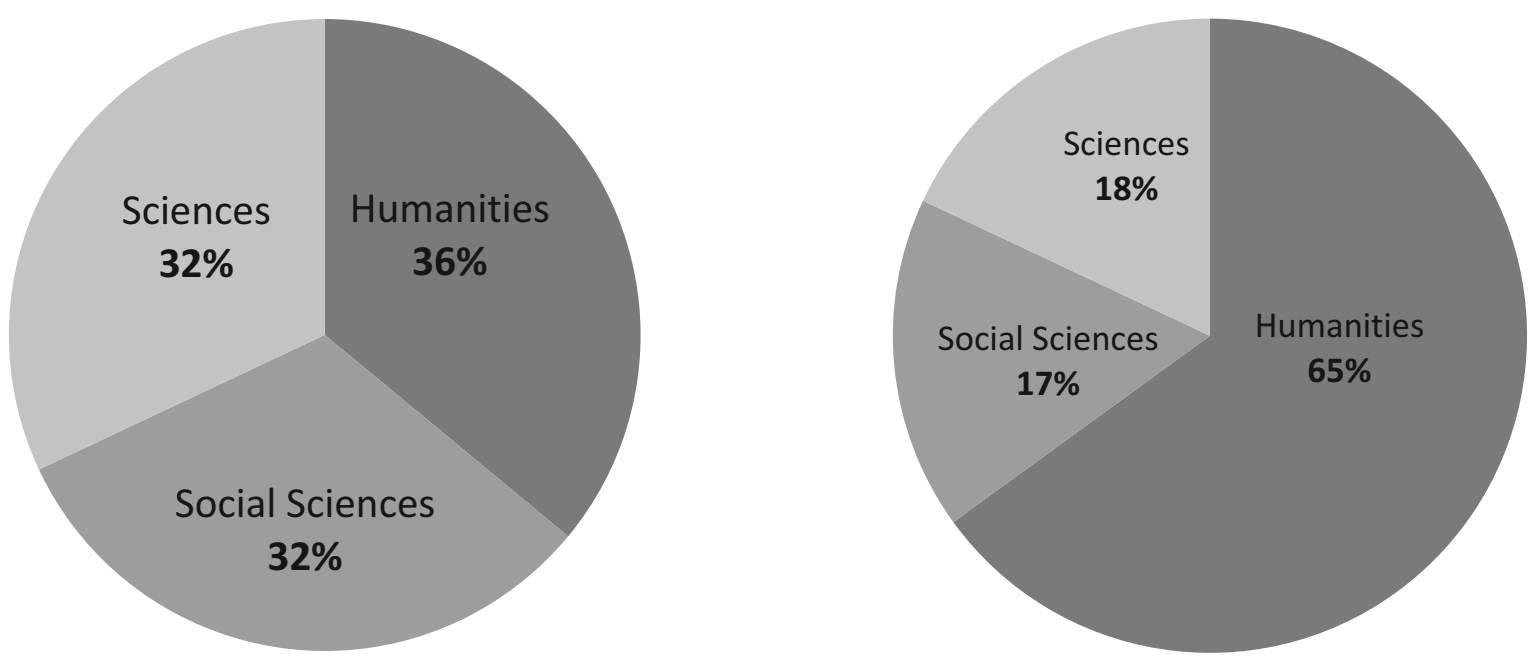

Figure 2. Breakdown of Subjects in Academic Libraries

Figure 3. Breakdown of Subjects in Public Libraries

sciences were tied at second (see figure 2). In public libraries, however, twothirds of all questions asked were about humanities subjects (see figure 3).

Table 5 provides more detail about the subject breakdown by DDC in both academic and public libaries.

DDC 000 (General Works and Bibliography): 7 Percent

DDC 000 was surprisingly well represented, equal to class 500 (science) and class 700 (fine arts). Germany and France had the highest number of questions in the 000 class, accounting for 15 percent of each of their subjectrelated questions. The subclass with the greatest use was library and information science.

DDC 100 (Philosophy), 200 (Religion), 400 (Language): 9 Percent The representation in the DDCs for philosophy, religion, and language is relatively scant; combined, they do not even make up one out of every ten questions asked. Almost half of the philosophy questions were in the subdivision of psychology, but no major subdivision in religion stands out. The most common subclass in the DDC for languages, after general works, is Germanic languages, all asked in countries where a Germanic language is official
(Germany, the Netherlands, and South Africa).

DDC 300 (Social Sciences): 28 Percent

The DDC for social sciences composed the largest single subject class, with more than one-fourth of all questions asked of all libraries. Of the 176 questions in this category, one-fourth fell into the 340s (law), and more than half (55 percent) of the law questions came from the South African institutions.

\section{DDC 500 (Sciences): 7 Percent}

While relatively low in total percentage, the class for sciences was represented in all countries. Its highest numbers were in South Africa and the Netherlands; its lowest were in Australia and Sweden.

\section{DDC 600 (Technology): 21 Percent}

The DDC for technology was the second highest subject class for all questions asked. The two major 600 subject areas-610 (medicine) and 650 (business)_combined to make up almost two-thirds of the questions asked in technology, increasing from 55 percent in 2006 to 73 percent in 2008. Again, South Africa stands out, as 32 percent of all its questions were in technology, and three-fourths of those were in medicine and business. It may be noteworthy that a heavy concentration of technology subjects for public libraries in the Netherlands and Sweden is offset by almost none in France and Germany.

\section{DDC 700 (Fine Arts and Recreation): 9 Percent}

As already mentioned, the Dewey class for the fine arts and recreation had a strong showing in public libraries. France had its strongest concentration here: almost a quarter of its questions were in the 700 class.

\section{DDC 800 (Literature): 9 Percent}

An unusually high concentration (25 percent) of questions in the DDC for literature fell into the area of rhetoric; the most common question regarded use of the Harvard style sheet. Also notable were questions in the Germanic literatures ( 25 percent) and French literatures (16 percent); by and large they were asked by users in their respective countries.

\section{DDC 900 (History and Biography): 10 Percent}

In the DDC for history, the subdivision with the most questions was in modern European history (32 percent), which includes World War II. Combined, the subdisciplines of biography and genealogy 


\section{FEATURE}

were second (23 percent). German libraries, both academic and public, stood out in this class, with 32 percent of their subject-related questions falling into history. Once again, there was a strong correlation between the geographic location of the library and the historical subject under investigation.

\section{Response time}

If, as is generally cited, virtual reference is the library's attempt to be where its patrons are when they need it, then responses within a reasonable time are assumed to be part of that convenience factor. And, unlike in-person, telephone, or chat exchanges, e-mail has no immediate acknowledgement from a human being unless an e-mail is sent with a notification of receipt or with the answer itself, or an apology that an answer cannot be found.

We noted immediately, in the 2006 data, that times varied greatly, ranging from a few minutes to several weeks! Belgium and Australia had the quickest average turnaround times (18 and 20 hours, respectively). South Africa and France had the longest (165 and 110 hours, respectively). It should be pointed out that those two countries also had the widest discrepancy between mean and median turnaround times.

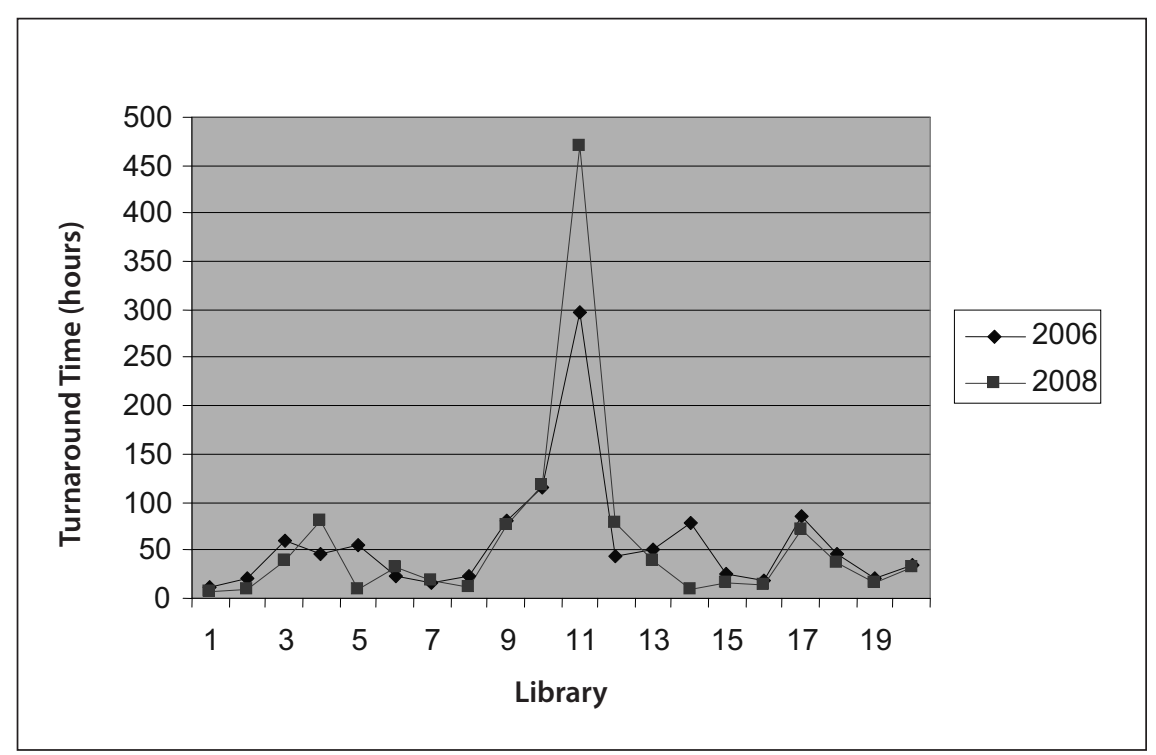

Figure 4. Comparison of Turnaround Times for Two Years
As for need-by and promised-by times, no public libraries in either of our sample years had need-by fields on their webforms-or they were not completed-so we compared their turnaround times only with what was indicated on their websites as a target. In 2006, academic institutions responded to patrons within the time the patron indicated they needed the information 87 percent of the time (according to 108 forms that collected that information). However, for that same year, 30 percent of the time neither public nor academic libraries responded within the time advertised on their websites (according to 394 transcripts). Belgian, Mexican, Australian, and German academic libraries scored the highest for responding within the advertised time, more than 90 percent.

In 2008, responses within advertised time improved somewhat: Only 27 percent of the academic libraries took longer than advertised, and only 17 percent of the public libraries took longer. Australian academic libraries maintained their lead with the fastest turnaround times (we did not have Belgian libraries to compare against in our 2008 transcripts). See figure 4.

As noted earlier, turnaround times varied widely. It's not surprising, of course, that some easier questions

.

Afrim dete Africa shows a still-long but respectable average turnaround time of ninety hours, with a twenty-hour median, and a much higher percentage of fulfilling its advertised service level.

In 2006, France also did not show well in turnaround times and meeting advertised service levels. Like all public libraries, France's showed a higher rate of subject-related questions than academic libraries, which may translate into more research required. The French libraries also cited print sources in 50 percent of their transactions, the most of any country. ${ }^{17}$

As mentioned earlier, our statistics for need-by and promised-by times are based on first response, which is not necessarily always the answer. So, even though the percentages for these are 
high throughout, the fact that in 30 percent were not responded to within the advertised, or promised-by, time in 2006 may indicate that greater effort is needed to be made to at least let patrons know a librarian is working on their questions.

In 2006, very few institutions had a need-by field on their forms. Those that did have the field almost always responded within the time needed.

The 2008 sample data also had relatively few need-by fields. However, eleven institutions advertised responses within a certain period of time on their websites. (We note these were websites that did not require authentication.) Of these, only one institution, an academic library, had both a need-by field and a Web form service claim, and it's interesting to note that this institution had very much the same percentage of success in meeting the criteria in both cases.

A German academic library included a need-by field, and they responded as requested in twenty-four of twentyfive transactions. The other four institutions with need-by fields were South African academic libraries, all of which complied within the requested time more than 50 percent of the time; only one complied nearly 100 percent of the time.

In 2008 service claims or advertised response-time targets, most libraries met service claims more than 75 percent of the time. The Slovenian library always responded in time, while one of the South African libraries never did.

One of our hypotheses was that over time, as staff became more familiar with the new service environment and the software and had more time to integrate virtual reference with the more traditional service forms, response times would improve. We did see improvement for the most part, but in a few cases_all academic_-response times actually got worse. But impressive improvements came in two academic libraries as well: one in Mexico and one in the United Kingdom (see table 6).

\section{CONCLUSIONS}

Analysis of the questions-asked disciplines in the virtual environment presents some unique patterns about how end-users seek information in the arts and humanities. Together they compose almost half of all questions asked in the virtual format in the countries studied; France and Sweden had the highest percentage, both with public libraries only. The pattern of a much higher percentage of subject-related questions in public libraries contrasts with the general virtual reference trend in academic libraries, which shows a much higher percentage of access questions. Since many of the access questions concerned connection problems or logging on to databases, the relatively fewer number may indicate that the arts and humanities disciplines require less database searching and that the users need specific answers instead.

It is interesting to speculate why questions in technology nearly doubled in the two years studied. In fact, medicine and business increased by almost 20 percent from 2006 to 2008. Such a dramatic shift was not noted in the other subject areas. Could there have been a world event in March-April 2008 that triggered the higher incidence? While it is impossible to guess at the reasons, one might speculate that the sinking economy, which began to be felt around the world in the months preceding the time of our data set, accounts for some of the increase.

One of our hopes in examining a second year of data was that we would see perceptible improvements in service, especially in the length of time it takes librarians to respond to questions. The 2006 data showed some turnaround times that were so slow as to seem in no way helpful to the patron. If a student wishes to know how to get a copy of an article from a missing journal issue for an upcoming class, it is probably of no use to find out about interlibrary loan practices and policies three weeks later. We had assumed that institutions with poor showings in turnaround times were probably new to virtual reference and had not fully integrated the service into their mainstream. We expected to see all institutions, especially those with the longest turnaround times, improve in two years' time.
The data did, in fact, show turnaround time improvement for most institutions. But for the two slowest institutions there was no improvement; in fact, the times became even longer. So while our data were positive for the most part, it cannot be said to "prove" the inevitability of improvement over time or with familiarity.

Finally, the data were clear about the differences in the type of questions asked by undergraduates versus those asked by graduates. Of all subject questions asked (as opposed to access or bibliographic), undergraduates asked almost two-thirds of them and graduates asked just over one-fourth. Question type was also one of the few areas of significant difference between the years, as graduate students asked 14 percent more access questions in 2008 than in 2006. It is probably reasonable to assume that graduates do considerably more of their own research than do undergraduates, but the increase in access questions is troublesome: Were websites more difficult to negotiate? Had databases and other resources been made more secure, thereby requiring more help? Was it the increase in two years' time of more complex electronic offerings and more students relying on the Web for library contact?

\section{FUTURE RESEARCH}

This study was limited to QuestionPoint transactions conducted via webforms e-mailed to and from libraries. Research is also needed to compare the nature of other access methods of virtual reference, such as chat and texting, in multiple countries and cultures. Such questions as whether the success of virtual reference services relies on cultural attributes are important to answer when developing and implementing reference services in countries of widely divergent cultures.

The researchers examined only languages they could read, resulting in a Western bias. QuestionPoint has libraries in China, Japan, Korea, Thailand, and the United Arab Emirates, for example, but none of the researchers could read the primary languages of 


\section{FEATURE}

these countries. An expansion into nonWestern languages might show whether the use patterns discovered in this paper are similar in Eastern cultures, such as the comparative research of e-mail reference in Israel, Japan, and Lebanon conducted by Shachaf, Meho, and Hara. ${ }^{18}$ It would be valuable to formally compare information-seeking behaviors in these disciplines with more conventional or face-to-face transactions. For example, it is traditionally held that philosophy questions usually make up the smallest percentage of questions asked, which this study bears out. Is this true of other disciplines? No matter what the access method to reference services is, does library reference use remain at similar levels for each discipline?

Finally, all virtual reference software has many features deemed to make the librarian's work more efficient. QuestionPoint has features to assist the librarian in providing the best answers and to track the answering process as it builds. For example, knowledge bases, referrals, and clarification requests are features meant to ultimately increase quality of service to the patron, if used properly. E-mailed webform transactions are a perfect way to judge whether this is happening and to what extent. A software efficiency study could shed light on cultural differences in attitudes toward cooperatively and efficiently serving patrons.

\section{References and Notes}

1. Susan Porter, "Chat: From the Desk of a Subject Librarian," Reference Services Review 31, no. 1 (2003): 57-67.

2. Ian J. Lee, "Do Virtual Reference Librarians Dream of Digital Reference Questions? A Qualitative and Quantitative Analysis of Email and Chat Reference," Australasian Public Libraries \& Information Service 35, no. 2 (June 2004): 95-110.

3. Doreen Sullivan, "Characteristics of E-mail Reference Services in Selected Public Libraries, Victoria, Australia," Reference Librarian 85 (2004): 51-80.

4. Keith Davis and Sally Scholfield, "Beyond the Virtual Shore': An Australian Digital Reference Initiative with a Global Dimension," Library Review 53, no. 1 (2004): 61-65.

5. Kate Davis, "AskNow Instant Messaging: Innovation in Virtual Reference," The Australian Library Journal 56, no. 2 (May 2007): 152-74.

6. Christelle diPietro and Bertrand Calenge, "Le Guichet du Savoir: Répondre aux Demandes de Contenus," Bulletin des Bibliothèques de France 50, no. 4 (2005): 38-43; Patrick Bazin, "The Guichet du Savoir: A Service for Knowledge Sharing and a Driving Force for Change," Library Management 27, no. 5 (2006): 423-29.

7. Claire Nguyen, "Les Services de Référence Virtuels en Bibliothèque Universitaire: Enjeux, Perspectives, Débats," Bulletin des Bibliothèques de France 51, no. 3 (2006): 38-43.

8. Ingeborg Simon, "Warum Verstecken Sie Sich? Warum Fragen Sie Nicht? Die E-Mail-Auskunft an Deutschen Universitätsbibliotheken," Bibliothek Forschung und Praxis 30, no. 3 (2006): 367-71.
9. Ingeborg Simon, "Weltoffen-Kundenorientiert-Professionell?" BuB Forum Bibliothek und Information 58, no. 3 (Mar. 2006): 245-49.

10. Alice Doek, "Chatten mit de Informatiebalie: Eén-op-één," Informatie Professional 8, no. 7/8 (July/Aug. 2004): 18-20.

11. Fatima Darries, "Internet Access and Use in Reference Services in Higher Education Institutions in South Africa," South African Journal of Libraries \& Information Science 70, no. 2 (2004): 72-85.

12. Eva Jonsby, "The Virtual Librarian Answers Your Questions," Scandinavian Public Library Quarterly 33, no. 3 (2000): 20-22.

13. Margaret Davies, "Creating a Virtual Reference Library: Experiences at Suffolk Libraries and Heritage," Program 35, no. 1 (Jan. 2001): 43-56.

14. Jill Beard, Neil Bottomly, and Rachel Geeson, "ASK: A Virtual Enquiry Desk: A Case Study," The Electronic Library 21, no. 6 (2003): 601-8.

15. Karen Cloughley, "Digital Reference Services: How Do the Library-Based Services Compare with the Expert Services?" Library Review 53, no. 1 (2004): 17-23.

16. Gobinda Chowdhury and Simone Margariti, "Digital Reference Services: A Snapshot of the Current Practices in Scottish Libraries," Library Review 53, no. 1 (2004): 50-60.

17. We noted the frequency of print citations or referrals but did not analyze it for this paper.

18. Pnina Shachaf, Lokman I. Meho, and Noriko Hara, "Cross-Cultural Analysis of E-Mail Reference," Journal of Academic Librarianship 33, no. 2 (2007): 243-53. 